to appear in: Albertazzi, L. (ed.) (2013). Handbook of Experimental Phenomenology.Visual Peception of Shape, Space and Appearance. Chichester: Wiley

\title{
The attribute of realness and the internal organization of perceptual reality
}

\author{
Rainer Mausfeld
}

The chapter deals with the notion of phenomenal realness, which was first systematically explored by Albert Michotte. Phenomenal realness refers to the impression that a perceptual object is perceived to have an autonomous existence in our mind-independent world. Perceptual psychology provides an abundance of phenomena, ranging from amodal completion to picture perception, that indicate that phenomenal realness is an independent perceptual attribute that can be conferred to perceptual objects in different degrees. The chapter outlines a theoretical framework that appears particularly well-suited for dealing with corresponding phenomena. According to this framework, perception can be understood as a triggering of conceptual forms by sensor inputs. It is argued that the attribute of phenomenal realness is based on specific types of internal evaluation functions which deal with the segregation of causes conceived as 'external' from those conceived as 'internal'. These evaluation functions integrate different internal sources of 'knowledge' about the potential causes for the activation of conceptual forms and provide markers by which conceptual forms can be tagged as 'external world objects'.

'Reality', in our ordinary usage of the term, denotes the entirety of things that actually exist. By 'reality' we mean the mind-independent world in which we are situated, about which our senses inform us and with which we can interact. In our ordinary modes of thinking, we regard all those aspects of our world as belonging or referring to reality, for which we have no reasons to assume that they are merely the product of mental activities, such as imagination, hallucination, or fiction. When we feel or think that our contact with reality becomes endangered due to other activities of our mind, such as imagination, dreaming, telling lies (i.e. contravening facts of reality), 'reality' itself becomes an object of our attention. The ways we deal with such situations suggest that we are equipped with intricate means to distinguish mind-internal productions from what we regard as mind-independent aspects of our world. The investigation of these means is a subject matter of perceptual psychology and, more generally, cognitive science. Notions of 'reality' and 'realness' can, of course, appear in other contexts different from perception theory, notably in ordinary discourse, theoretical physics, and philosophy. Fortunately, however, the specific issues that show up in these other contexts have no bearing (or only in a highly indirect way) on issues of perceptual psychology. Theoretical issues of perception theory that can be subsumed under the heading of 'phenomenal realness' are more easily recognisable when we do not confuse them with issues associated with 'realness' in other domains. 
In the context of epistemological issues, the distinction between mind-internal productions, on the one hand, and what we regard as mind-independent aspects of our world, on the other, was first intellectually grasped and made the target of systematic enquiry by the Pre-Socratic philosophers. They observed that different senses can lead us to different beliefs about the world (think of a rod half-dipped in water). Since then, the senses have not been considered trustworthy or reliable for acquiring true knowledge about the 'real world'. The concepts of 'objectivity' and 'theoretical knowledge', which have been established by early Greek philosophy, became the foundational pillars for the development of the natural sciences. In the course of these developments, a fundamental split has emerged between the world of everyday experience and the world as pictured by intellectual enquiry, i.e. physics.

Physics aims at developing a theoretical picture of the mind-independent world and has brought forth, in its theoretical development, its own notion of 'real'. In physics, all entities can be credited with the attribute 'real' that figure in the currently best explanatory accounts of physics. Accordingly, gravitational fields, fermions, or superstrings can be regarded as real in this sense. At the same time, we have preserved in our ordinary locutions a notion of 'real' that pertains to the 'external world' as conceived in our ordinary modes of thinking. Accordingly, rivers, stones, trees, chairs, or persons can be regarded as elements of the mindindependent reality underlying our experiences and hence as real in this sense. Our ordinary usage of the notion of 'real' has given rise to highly intricate ways of dealing, in everyday life, with all sorts of tensions between what is regarded as appearance and what is regarded as real. Some of these aspects have been made the target of systematic enquiry in various fields of the cognitive sciences, such as developmental psychology (e.g. Flavell, Flavell, and Green 1983), or primate ethology (e.g. Krachun, Call, and Tomasello 2009). Corresponding investigations usually proceed by taking our ordinary conception of reality as a matter of course and focus on properties of certain epistemic relations that characterize our handling of the relationship between what we regard as real and what we regard as apparent or deceptive.

In the context of perception theory, in contrast, we do not want to take our common-sense notion of 'real' for granted and simply regard 'real' as an attribute that befits the entities that figure in our ordinary conception of a mind-independent world. Since the very beginning of perceptual psychology, it has been observed that a perceptual entity, such as a concrete object or an event, can appear in some way as 'real', even though it is clearly recognisable that there is no corresponding entity in what we conceive as the external world (think of trompe-l'œil painting or of an object on a computer screen). Therefore, it is a task of perception theory to identify the internal principles by which perceptual entities and their attributes are elicited on the occasion of sensory inputs, and by which the attribute 'real' is conferred to perceptual entities. 


\section{Historical roots of the problem of perceptual realness/unrealness}

Although corresponding issues have been at the heart of Gestalt psychology and ethology, they rarely have been appreciated explicitly in the history of perceptual psychology. This is hardly surprising because a kind of naïve realism is deeply built-in into our common-sense conception of perception. We are convinced that the objects and attributes that figure in our percepts are normally caused by, and mirror corresponding objects and attributes in the mindindependent external world. The predisposition to take perceptual entities for 'things in the real world' is the distinguishing mark of our mental activity. Hence, this predisposition is usually not regarded as a theoretical problem in need of explanation but as a matter of course. Perceptual psychology has, almost without exception, tacitly proceeded on the basis of naïve realist conceptions (albeit often in technically sophisticated variants, such as inverse optics, or Bayesian approaches). Accordingly, perceptual psychology has been entirely oblivious of the fact that in the context of perception theory, 'real' has to be regarded as an internal attribute, which is conferred to perceptual entities in accord with specific internal principles. The nature of this perceptual attribute is as much in need of explanation by deeper principles as, say, the nature of the attributes 'colour' or 'form'. Only very few psychologist, such as Störring (1900), Stumpf (1906a), Jaensch (1911), Musatti (1926, 1964; cf. Poli 1999), Metzger (1941), or Michotte (1960) recognised that 'real' is a perceptual attribute whose properties are determined by the internal structural organization of perceptual categories.

Gustav Störring, a pupil of Wundt, dealt with the attribute of realness in the context of hallucinations and pseudo-hallucinations. Hallucinations are experienced as real, while pseudohallucinations, despite being vivid and rich in detail, are experienced as unreal. The perceptual objects and their attributes, such as form or colour, of pseudo-hallucinations are experienced as phenomenally present; the objects themselves, however, bear no relation to the ambient space of the perceiver, and are experienced as being not real (Störring 1900, 65). Drawing on Störring's observations, Erich Jaensch, in his investigations of perceptual space, conjectured that "a necessary condition for a visual experience to be regarded as real is its integration into ambient space" (Jaensch 1911, 469). He observed that "the impression of reality can take on different degrees of conspicuity” (ibid., 471), and that ,a visual phenomenon appears completely unreal, if the definiteness of localisation is minimal, i.e. if the corresponding phenomenon bears no relation to the ambient space." (ibid., 481) He supposed that "a relatively poor definiteness of location and relatively poor conspicuity of reality impression are concurrent phenomena" (ibid., 479/480). Jaensch, using picture perception as an illustration, observed that the "conspicuity of the impression of reality" is in a similar way open to gradation as the "conspicuity of depth impression" (ibid., 471). He contended that "the experience of reality is as much preformed by elementary functions of the perception of space as are the elements of the concept of object and the abstraction of form." (ibid., 467)

The treatment of the issue of the internal attribute of realness remained, however, cursory and was empirically based on ad hoc observations only. Michotte (1960) was the first to tackle the 
issue in a more systematic way. In his theoretical perspective, Michotte put himself in sharp contradistinction to core presumptions about perception that are still prevailing today. In particular, he regarded that idea as profoundly inappropriate that elementary attributes, such as colour, shape or movement, constitute the basis from which meaningful perceptual categories are derived or built up, and that the percept can essentially be derived or inferred from the structure of the input. In contrast to traditional conceptions, which fundamentally misconstrue the role of the sensory input, Michotte (1941) emphasised that the role of the sensory input is not to provide material that can "be combined, related or even modified by certain psychological processes, predominantly under the influence of experience. ... Its role on the contrary seems to be confined to the triggering of endogenous constructive processes which obey their own laws of organization, are largely autonomous and independent of experience, and bring forth the edifice of our phenomenal world." ("Le rôle des excitants n'est pas, comme on l'a cru longtemps, de donner naissance à des 'sensations' qui seraient combinées, liées les unes aux autres, et même modifiées par certains processus psychiques, sous l'influence prépondérante de l'expérience acquise. ... Ce rôle paraît au contraire se réduire au simple déclenchement de processus constructifs endogènes obéissant à des lois d'organisation propres, largement autonomes et indépendantes de l'expérience, et qui aboutissent d'emblée à l'édification du monde phénoménal.”)

Michotte thus recognised that the principle explanatory burden of accounting for perceptual achievements, such as assignments of the attribute 'causal' to events, or the attribute 'real' to concrete objects, events or situations, cannot be put on associative, inferential or interpretative processes. Rather, underlying such achievements "seems to be a kind of 'prefiguration' of abstract concepts, the mental 'categories' of substance, reality, and causality" (Michotte 1960/1991, 44/45). Consequently, Michotte regarded perceptual attributes, such as 'causal' or 'real', which have traditionally been attributed to interpretative and cognitive processes, as being perceptually primordial and as immediate as, say, form or three-dimensionality. On his view, these perceptual attributes are specified by a predetermined internal structure, and are activated by specific input conditions (e.g. Michotte 1946/1963, 87).

Michotte's theoretical perspective again draws attention to fundamental issues of perception theory that have been misapprehend or even entirely ignored by traditional approaches. It has to be conceded, however, that Michotte presented his theoretical ideas in a rather diffident way, mostly in the form of scattered remarks rather than in explicit systematic expositions. But his theoretical conception can be clearly gathered from his corresponding remarks. It also can be recognised from the specific perceptual issues that he addressed, notably amodal completion, phenomenal identity and permanence, phenomenal causality and apparent reality, as well as in the specific way in which he experimentally approached these phenomena. In his theoretical formulations, Michotte was bound to express his idea in more intuitive, vague, and even incoherent terms. This is hardly surprising because he was conceptually and methodologically at the crossing point of different and partly conflicting traditions whose embroilments and obscurities he inherited. All the same, Michotte was able to achieve decisive in- 
sights into the nature of perception and to corroborate them in a highly productive way through a rich body of experimental evidences. Michotte's theoretical insights have remained almost completely unappreciated by current orthodoxy, notwithstanding the fact that some of his experimental ideas and findings have been assimilated into traditional accounts.

\section{Experimental phenomenology}

Michotte called his approach "experimental phenomenology". Through Oswalt Külpe, Michotte became acquainted with the work of Brentano and Stumpf, who had a formative and lasting influence on him (other sources were von Ehrenfels, Meinong and Husserl). Brentano emphasised the vital necessity of a descriptive psychology (to which he also parenthetically referred to as phenomenology) which had to precede any explanatory accounts in psychology. He set out "to construct a psychological theory without having to accept reductionist hypotheses of any kind; or in other words, without having to relate psychic phenomena directly to physical, chemical or physiological ones." (Albertazzi 2006, 94). Stumpf, a pupil of Brentano, conjoined core ideas of Brentano with those of Ewald Hering, and explicitly championed the combination of a strong experimental orientation with a phenomenological stance. The approach of experimental phenomenology emerged, almost independently, from two original sources, viz. Hering and Brentano. Stumpf tied core elements from both sources together and explicitly advocated an approach of experimental phenomenology and conducted it in a systematic way.

Stumpf (1906b), in his “On the Classification of the Sciences”, assigned phenomenology a neutral position and regarded it as a discipline of its own, which neither belongs to natural science nor to the humanities. According to Stumpf (1906b, 28), phenomenology deals with the "immanent structural laws" that can be found in the phenomenal appearances themselves. He regarded descriptive psychology as a kind of preparatory and propaedeutic enterprise in the service of exploring and explaining "psychic functions" (Stumpf 1917, 8), i.e. for the purpose of an explanatory psychology. Careful unprejudiced and undistorted descriptions of phenomena have to precede the formulation of experimental and theoretical ideas. As Koffka $(1935,73)$ put it: "For us phenomenology means as naive and full a description of direct experience as possible." A phenomenological stance requires a focus on "the experienced phenomena such as they offer themselves, with their vague and fading contours, with all their indeterminateness, in twilight and chiaroscuro.“ (Gurwitsch 2009, 170)

In the context of the cognitive sciences, the idea of a "naïve and full description of phenomena" is notoriously fraught with problems and is tied to assumptions that are dubious at best. There is, however, a more specific requirement for an 'unbiased' description of phenomena that can be justified on methodological and theoretical grounds in the context of developing explanatory accounts of perception: If one aims to reveal fundamental principles underlying perception, the descriptions of perceptual phenomena and achievements must not be contami- 
nated by physical or physiological considerations. Stumpf $(1917,7)$ credited Hering for having once and for all revealed the "detrimental immixture" ("schädliche Hereinmengung") of physical aspects into the description of perceptual phenomena. Hering $(1878,51)$ considered it as a "primordinal requirement" to start with the perceptual phenomena themselves and "to strictly avoid mixing-up perceptual phenomena with their physical or physiological causes or to derive from the latter any principle of classification." He deplored that "this matter-ofcourse requirement continues to be violated." Hering repeatedly and insistently warned against the infiltration of physical considerations into the investigation of mental phenomena and emphasized that "it is essential to begin with enquiries that abstain altogether from the causes and conditions of their arising" (Hering 1920, 24). Several others have pointed out the detrimental tendency to impose the physical causes of perceptual phenomena on their classification and description and blamed it as a source of severe confusions and errors in perceptual psychology (e.g. Marty 1879, 127). Enquiries into the abstract principles on which perceptual achievements are based should avoid, in their theoretical formulations, any notions of the 'true' antecedents of the sensory input among the infinite set of potential causal antecedents. The percept as such, say of a cube, does not testify to its own external origin; it can be elicited by an external object, by certain properties of the incoming light array as produced by a screen, or from appropriate neural stimulations of the visual system. Accordingly, internalist approaches to perception (cf. Mausfeld 2010), as exemplified by the Gestaltist or ethological enquiries, have cautioned against the natural propensity to surreptitiously borrow internal notions and categories, such as 'perceptual object', 'surface', 'shadow', or 'illumination', from the output of the perceptual system and to use them for a description of the alleged external causal antecedent.

\section{Michotte's observations on phenomenal realness}

The notion of phenomenal realness that is the target of Michotte's enquiries pertains to a specific internal attribute that can be conferred, according to specific internal principles, in different degrees to perceptual entities. It refers to the impression that a perceptual entity is perceived as having an autonomous existence in our external mind-independent world. The attribute of 'real' in this sense means that a perceptual entity is internally singled out by a kind of marker that assigns it a special status in our mental assessment of the relation of the experiential phenomena and our ambient mind-independent world (as perceived). In the perceptual experiences of our everyday life, almost all of our perceptual entities are, under normal conditions, marked as 'real', so that this attribute is not salient as a perceptual attribute. Only when we experience ourselves in situations in which our being-in-direct-contact-with-the-world is partly disturbed or broken, we encounter a distinction between perceptual entities that are perceived as 'real' and those that are not.

Michotte observed that the entities that figure in our experience, notably concrete objects, events or situations, can exhibit different degrees of phenomenal realness. Phenomenal real- 
ness is, as Michotte $(1948 / 1991,181)$ claimed on the basis of his observations and findings, "an independent dimension of our visual experience" that has its own structural properties and triggering conditions.

Although this had already been occasionally observed before, notably by Jaensch (1911), Michotte was the first to make this attribute the target of systematic investigation and to show "that gradual variations in reality correspond to progressive variations in the stimulation, which are both well defined and controllable." (Michotte 1948/1991, 184) He held that "a variety of considerations and a good deal of research force us to conclude that any perceptual structure possesses among its characteristic features not only its qualities, intensity, duration, extent, etc. but also a special property of 'reality' or 'unreality', which can vary in degree as do the other sensory dimensions." (Michotte 1960/1991, 194).

Michotte also recognised "that three-dimensionality and reality are different properties of our perceptions and must be considered as independent dimensions of our visual experience." (ibid., 181). More generally, we have to distinguish the phenomenal presence, livelines or vividness (cf. Koffka 1922, 557) of a perceptual attribute from the phenomenal realness of its object. Factors that increase the vividness of the perceived three-dimensionality of twodimensional figures had been studied before, e.g. by Benussi (1911) and Kopfermann (1935), and in the dynamic case by Musatti (1924), and Wallach and O'Connell (1953). Phenomenal realness, however, requires that the perceived object is perceptually released and decoupled, by suitable experimental manipulations, from its mediating carrier and receives a kind of autonomous existence. Although the degree of three-dimensionality and phenomenal reality tend to co-vary for certain classes of situations, the two dimensions do not coincide and also have to be clearly distinguished on theoretical grounds (because they pertain, as is argued below, to different architectural components of the perceptual system).

In some of his experiments on phenomenal realness, Michotte used as stimulus configurations very elongated perspective images (as shown in figure 1), which were viewed monocularly from an extremely oblique lateral perspective. The geometrical object depicted in figure 1 appears as a three-dimensional solid form. However, the perceived three-dimensional form has no definite location in our ambient space, exhibits an ambiguous orientation, lacks the distinctive material qualities of taut surfaces and does not exhibit the right transformational properties that go along with dynamic changes in the spatial relation between observer and object. Accordingly, it has a low degree of phenomenal realness, i.e. does not appear to have an autonomous existence in our mind-independent world. 
A

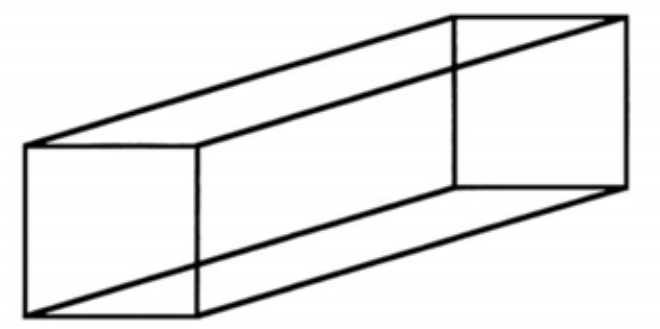

Fig. 1: Michotte figure

If this figure is monocularly viewed, from an appropriate distance, from the end marked B, with the eye placed almost in the same plane as the paper, "one sees an object shaped more or less like a cube or parallelepiped (depending on viewing position), and this sometimes has a disconcerting character of reality, which is as good as that produced by the best processes of stereoscopy. ... The effect of the volume can be so intense that if one suggests to the observer to attempt the manipulation test and to pass a rod through the object, the observer does not hesitate to try and is extremely astonished to find that the rod hits the paper, and slides along its surface above the object! ... The impression of reality is so powerful at the time that it is able to overpower any effect of the observer's belief in the unreality of the object." (Michotte 1948/1991, 182-184; cf. Phemister 1951).

In figure 1, the two-dimensional object is tied to the plane of the paper and has a definite location on the page on which it is drawn. However, the location of the perceived threedimensional form with respect to the two-dimensional reference frame of the paper bears some kind of indefiniteness. Under Michotte's oblique viewing conditions, the perceptual object becomes somehow decoupled from its mediating carrier. Such a decoupling is obtained by inducing a conflict between the orientation of the surface of the page with the direction of the lines along which the perceived object is projected, so that the surface of the paper can no longer be perceived as the carrier for the perceived three-dimensional object.

The degree of realness of objects as the one depicted in figure 1 can be increased by experimental manipulations of factors that result in a stronger perceptual segregation of the perceived three-dimensional object and its mediating carrier (such as stereo disparity, texture and material qualities, shading, or dynamic transformations). The degree of realness can also be increased by a spatial anchoring of the perceived object and a corresponding assignment of a definite location. The degree of phenomenal realness is strongest when a perceptual object has a definite location in the ambient space of the observer. Interestingly, however, some degree of perceptual realness can also be achieved with respect to suitable frames of references that are different from the ambient space of the observer. 
In order to enhance the degree by which a perceptual object is assigned some definite location in perceptual space, one can embed it into a context of other perceptual objects such that the spatial relations between these object establish a perceptual organization in terms of an autonomous spatial frame of reference. There is a kind of continuous path along which Michotte's experimental situation as shown in figure 1 can be extended to classes of stimulus configurations that are typically discussed under the heading of picture (or film) perception. These classes of stimulus configurations were therefore a natural target for Michotte's investigations of the attribute of realness.

The painting shown in figure 2 illustrates these configurations and the kind of perceptual intricacies associated with it.

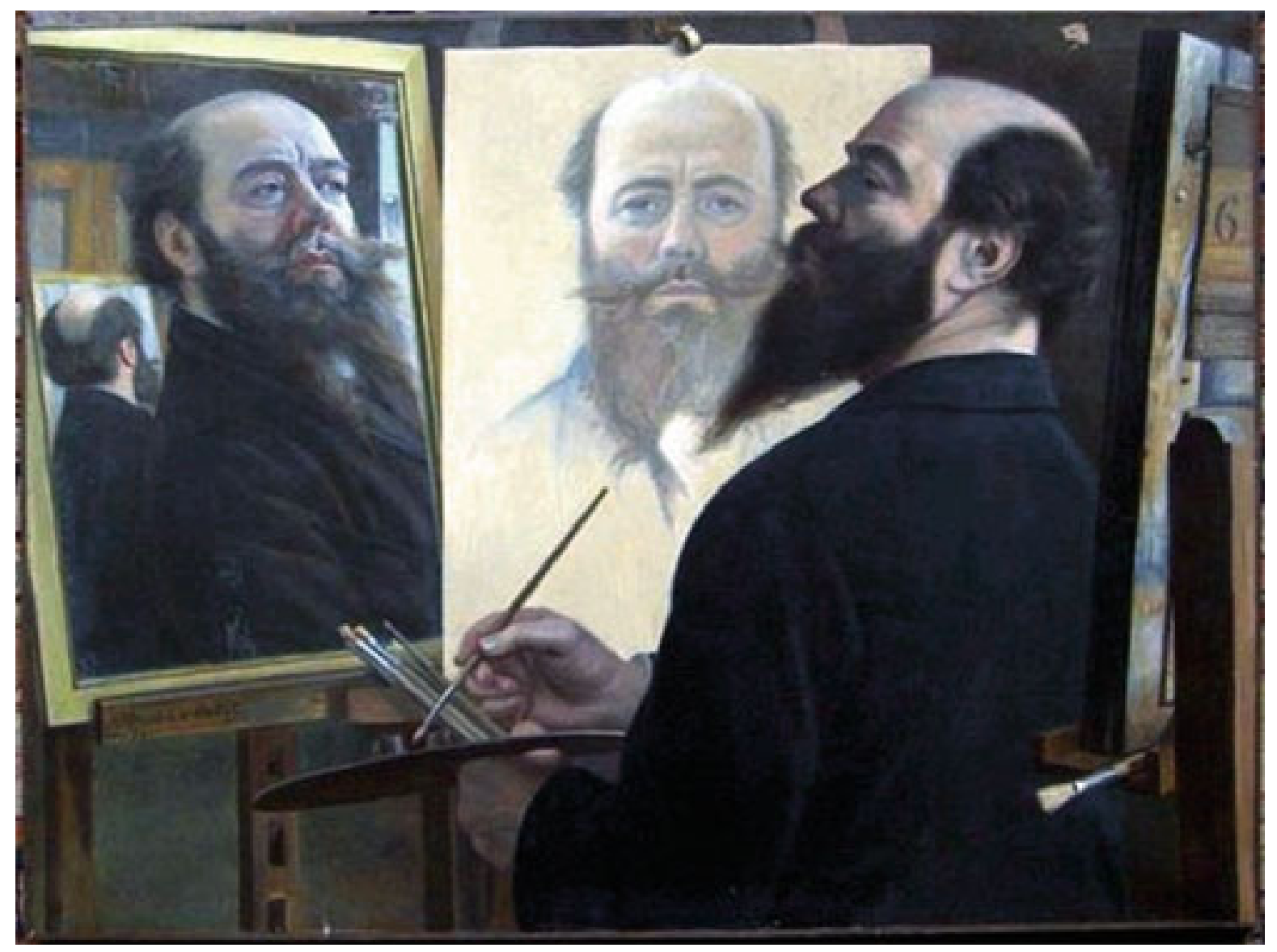

Fig.2: Alfred Le Petit, Autoportrait, 1893

Four of the depicted figures are particularly salient as representing heads. At least three of them are immediately seen as representing the same head. With respect to the ambient space of the observer, all four figures are of the same type, namely two-dimensional drawings on a canvas. As drawings, they are phenomenal real. They have a definite location in the ambient space of the observer and are open to all sorts of manipulations by the observer. In the context of the entire situation depicted in the painting, they become, however, somehow decoupled from their mediating carrier, the canvas, and receive, to different degrees, a kind of autono- 
mous existence. The rightmost head has the highest degree of phenomenal realness as it appears to be unmediated with respect to the picture space spanned by the reference frame of the depicted situation. Although the perceived three-dimensionality of this perceptual object is not fully vivid, intrinsic attributes, such as material qualities of skin, beard and clothes, are appropriately specified. Furthermore, this head belongs to a person who is perceived as occupying a definite location in the spatial reference frame provided by the picture space and whose visible parts are determined by the spatial relations within that frame of reference. In contrast, the head on the left next to it appears to be clearly mediated by a marked-out surface in the picture space. Hence, it does not appear as phenomenal real. If it were a phenomenal real object, its intrinsic attributes would have to be more appropriately specified, and its boundaries must be motivated by the layout of its ambient space. This head therefore constitutes a perceptual object of a type different from that of the rightmost head: It is perceived as an artefact, namely as a drawing. The head on the left to it is also mediated by a marked-out surface in the picture space, and hence receives a low degree of phenomenal realness. However, its spatial location, its intrinsic attributes and other aspects of the entire situation open up the option to subject it to internal causal analyses that pertain to reflection properties of mirrors. Accordingly, the perceptual object 'mirror' itself can be perceived as having some degree of phenomenal realness. The rightmost head and the head seen in the mirror stand, with respect to the reference frame of the picture space, in a spatial relation that conforms to the requirements of internal causal analyses pertaining to 'mirror situations'. (The internal causal analyses pertaining to 'mirror situations' presumably have their own proprietary constraints and criteria for violations, which cannot simply be derived from corresponding optical considerations.)

In his approach to phenomenal realness, Michotte astutely picked out phenomena that most strikingly reveal perceptual achievements of fundamental importance and that can be experimentally studied using rather simple equipment. The visual domain offers a plenitude of corresponding phenomena and likely seems to play a prominent role in the assignment of the attribute 'real'. Nevertheless, this attribute is not tied to a specific modality but pervades perception in general. We can therefore find an abundance of theoretically important phenomena on phenomenal realness in addition to and beyond the ones investigated by Michotte. These phenomena range from rather simple sensory ones to the most complex perceptual achievements. In olfaction, for instance, an odour whose intensity does not vary with the movements of the observer over larger distances and changes in direction will receive a lesser degree of realness than an odour that varies with spatial position. Among the most complex perceptual entities to which a degree of phenomenal realness can be assigned are ones that pertain to "self" and "body", as for instance in phenomena of paradox location and ownership experiences of body parts or the entire body induced by visual-tactile incongruences (e.g. Armel \& Ramachandran 2003; Lenggenhager, Mouthon, and Blanke 2009). In applied areas, experiential aspects that are closely related to phenomenal realness are discussed under headings such as immersion, presence, or telepresence (e.g. Steuer 1992; Lee 2004). 


\section{Phenomenal duplication}

In stimulus configurations in which the spatial and temporal relations among perceptual objects establish a separate frame of reference that is decoupled from the spatial and temporal reference of the observer, a conflict arises with respect to the attribute of realness. A kind of perceptual scission occurs that yields two layers of 'interpretations', with independent and conflicting assignments of perceptual realness. In the area of picture perception, the phenomenon that pictures can generate an in-depth spatial impression of the scene depicted while at the same time appearing as flat two-dimensional surfaces hanging on a wall is investigated under the heading 'dual character of pictures' (cf. Mausfeld 2003). Other instances in which we can find corresponding perceptual scissions pertain to movies and theatre play. Michotte (1960/1991, 191f.) referred to such a scission as "phenomenal duplication" and cited as a particularly striking example "the duplication of space and time that occurs in theatrical representation". "The space of the scene seems to be the space in which the represented events are actually taking, or have taken, place and yet it is also continuous with the space of the theatre itself. Similarly for time also, instants, intervals, and successions for the spectators belong primarily to the events they are watching, but they are left nevertheless in their own present. A further peculiar phenomenon that vividly confirms the unreal character of the representation concerns the way in which an interval, which really lasts usually a matter of minutes or seconds, comes by this process of transportation to have the apparent significance of days, months, or even years."

In line with his tenet of a "primacy of dynamic over static aspects of experience" (Michotte 1953/1991, 216), Michotte regarded the investigation of events as of pivotal importance. Perceptual phenomena pertaining to events bring to mind in a particularly striking way that we are obviously endowed with a specific perceptual capacity by which we can visually attain aspects of perceptual objects that pertain to their hidden dispositional powers and propensities. Due to this capacity, which is determined by the internal structural organization of perceptual categories and the specific causal analyses which appertain to this organization, we are not only able to identify specific kinds of objects and stuff, but also to visually grasp an abundant variety of 'hidden' properties of objects that go far beyond purely visual attributes. As Schapp (1910, p. 21f.) recognised: "The things as perceived own a surplus of properties which are not simply coloured surfaces and which cannot be obtained by associations or inferences from other sensory properties. ... One directly sees tenacity, brittleness, obdurateness, bluntness and many other attributes for which we lack linguistic descriptions." The same holds for events. We immediately perceive the invisible forces and energies that give rise to the spatial and temporal properties of events.

The characteristic properties of events are in a sense more abstract than that of concrete stationary objects. The constitutive aspects of events pertain to a temporal relational structure; the elements themselves, however, on which such a temporal structure is defined, seem to 
play a subordinate role only. Accordingly, an event can receive some degree of phenomenal realness, even when the carrier objects on which the event is defined are of a type that does not support this event or is not coherent with the kind of type required by the event. For instance, in the well-known Heider-Simmel demonstration (Heider \& Simmel, 1944), in which a small and a large triangle and a small circle move against and around each other and an open rectangle, we unanimously perceive this event in terms of attributes, such as chasing, looking for, hiding, conferring, being furious or frightened, etc. Although we irresistibly perceive self-propelling objects with intentional attributes in this demonstration, we are still aware that we actually see only geometrical objects moving, again a kind of duplication. The (abstract) event itself can receive some degree of phenomenal realness, while its underlying objects do not. As in the case of picture perception, one kind of percept does not vitiate the other, both can exist simultaneously as two layers of perceptual interpretation, as it were. Despite the fact that we ascribe in the Heider-Simmel demonstration anthropomorphic properties to the perceptual objects, it would never occur to us to actually interact with these objects. In this demonstration, duplication is primarily provoked by two factors. Firstly, the spatial and temporal reference frame in which the event is located is different from the one in which the observer is situated. Secondly, the type carrier objects on which the event is defined are in conflict with the type of carrier object that is required for the kinds of attributes elicited by the event.

\section{Structural regularities underlying duplication}

Michotte's findings and a plethora of related phenomenological observations suggest that there is a kind of internal logic of how the attribute of realness is assigned to perceptual objects. This logic reveals itself most strikingly in the case of duplication or perceptual scission into two layers of perceptual 'interpretation'. It is therefore instructive to distil from corresponding observations some structural regularities that characterise the occurrence of duplication in a more abstract way.

Our phenomenal percepts can be regarded as being logically organized in a hierarchical manner. As a grossest division, we can assume that "frames of reference" (Koffka 1935) (which themselves can be hierarchically organized) are at the top level of this hierarchy. Intuitively, duplication occurs in stimulus situations, in which perceptual objects are organized in a way that yields a spatially and temporally autonomous reference system different from the overarching frame of reference in which the observer is situated and which is perceived as 'reality' by the observer. Accordingly, these perceptual objects receive their relations and attributes (including that of 'realness') from their respective frame of reference. At the same time they also have some sort of perceptual existence in the overarching frame of reference, in which the observer is temporally and spatially situated. This unique frame of reference ordains our feeling of 'being-in-the-world' and is perceived as 'reality'. Normally it is phenomenally not salient as a reference frame and hence itself not the object of our attention. 
We can, in a highly idealised (and somehow metaphorical) way, conceive of a reference frame as a structure, consisting of a domain of 'perceptual objects' together with a set of relations and operations that are defined on these perceptual objects. Let $\boldsymbol{\Omega}$ denote the overarching system of reference 'reality'. A reference frame $\boldsymbol{\omega}$ is a substructure of $\boldsymbol{\Omega}$ if the domain of $\boldsymbol{\omega}$ is a subset of the domain of $\boldsymbol{\Omega}$ and if the restriction of the relations and operations of $\boldsymbol{\Omega}$ to the domain of $\boldsymbol{\omega}$ yields the corresponding $\boldsymbol{\omega}$-relations and $\boldsymbol{\omega}$-operations. In this case, we can say that $\boldsymbol{\omega}$ can be consistently extended to $\Omega$. A reference frame is called perceptually autonomous if it cannot be consistently extended to $\Omega$.

If there is no consistent extension of a reference frame $\omega$ to $\Omega$, the percept tends to exhibit a duplication, i.e. a kind of perceptual scission into two simultaneous layers of perceptual 'interpretations' or simultaneous mental perspectives (cf. Mausfeld 2011). In an autonomous frame of reference, constraints pertaining to certain operators, transformations or entailment relations of $\boldsymbol{\Omega}$ can be liberalized or set mute. Examples are constraints derived from transformations associated with the movements of the observer, or perspective transformations pertaining to scenes within pictures (see Pirenne 1970, 96ff.).

Examples for autonomous frames of reference can be abundantly found in picture or movie perception. They are particularly striking in cinema because abrupt transitions occur from one scene to an entirely different one, without any displacement of the observer. The reference system rendered by the movie screen terminates abruptly and unprovoked in $\Omega$ rather than because of an occlusion by other perceptual objects in $\Omega$ (which distinguishes a realistic scene watched on a movie screen from the same scene viewed monocularly through a window). In picture perception, we can see the canvas as an object in $\Omega$, while at the same time the canvas functions as a medium for establishing a subordinate frame of reference which exhibits its own relations between perceptual objects. The depicted objects and their attributes and relations can be perceived, under suitable conditions, as having themselves a high degree of realness, even though they are not subjected to the appropriate kind of $\boldsymbol{\omega}$-transformations induced by a moving observer.

Situations in which a phenomenally vivid perceptual object in some autonomous reference frame $\boldsymbol{\omega}$ receives a comparatively low degree of phenomenal realness seem to activate further internal causal analyses that check for superordinate frames of reference with respect to which the phenomenal realness of these objects is re-established.

These structural considerations can be exemplified by the painting shown in figure 2 . The canvas of this painting is an element of $\Omega$, i.e. a perceptual object in the ambient space of the observer. The scene depicted on the canvas establishes an autonomous reference system. Within the depicted scene, two other subordinate reference systems are brought forth by the perceptual objects in the depicted mirror, and by those on the depicted white drawing paper, respectively. 
Among the perceptual objects seen in this painting, there are four perceptual objects of the type 'head'. As painted flat figures on a canvas, these four heads have the same degree of phenomenal realness with respect to $\Omega$. At the same time, these perceptual objects are ordained autonomous existence with respect to the subordinate systems of reference that are spanned by the entire scene depicted on the canvas $\omega$, the scene in the depicted mirror $\omega_{1}^{\prime}$, and the scene on the depicted drawing paper $\omega_{2}^{\prime}$, respectively.

Accordingly, the four heads receive different degrees of phenomenal realness. The reference frame 'mirror' $\omega_{1}^{\prime}$, is not autonomous with respect to $\omega$, i.e. spatio-temporal relations between perceptual objects in the mirror can be consistently extended to spatio-temporal relations in the superordinate reference system $\boldsymbol{\omega}$. Accordingly, objects in the mirror have a high degree of realness with respect to $\boldsymbol{\omega}$, namely as perceptual objects of the type ' $\boldsymbol{\omega}$-head seen in a mirror'. In contrast, the reference frame $\omega_{2}^{\prime}$ that is spanned by the scene on the depicted drawing paper is autonomous with respect to $\boldsymbol{\omega}$ (for instance, the terminating points of this figure are causally unmotivated with respect to $\boldsymbol{\omega})$. Accordingly, this head receives a much lower degree of realness, both with respect to $\omega$ and to $\Omega$, than the other ones.

\section{On the status of phenomenological observations in perception theory}

In the context of psychological enquiries that aim at explanatory accounts of perception, the question arises as to the status of phenomenological observations. It is well known that the functional architecture of our brain almost completely hides the functioning of the perceptual system from our conscious experience, and that what we consciously perceive is only a kind of end product of an entire orchestra of systems involved in perception. Particularly the Gestaltists pointed out that core organizing principles of perception are independent of our explicit awareness and conscious control. Furthermore, there are many types of theoretically important observations on perception that are for principle reasons more or less inaccessible to a phenomenological approach, such as ethological findings. In face of these facts, the preparatory and propaedeutic function that, for instance, Stumpf and Hering assigned to phenomenological observations cannot simply be taken for granted but requires justification.

Phenomenological observations rely on (predominantly) conscious experience as experienced from the first person point of view. They thus are based on the integral person as the unit of analysis. The questions that emerge and the kind of concepts used in the context of experimental phenomenology and phenomenological approaches in general clearly indicate that enquiries are guided by presumptions that are only warranted with respect to 'persons' as units of analysis. The structure of experience that is mirrored in phenomenological observations is therefore the product of our integral mind, as it were, and cannot be contributed to any of its components. It is entirely alien to phenomenological approaches to distinguish contributions of different components of our mind. The same applies to our ordinary conceptions of perception. Our common-sense conceptions have no need to distinguish between the contribu- 
tions of different components, and thus between the output of a specific system and the potential uses it is put to by subsequent systems. They therefore tend to identify the output of the perceptual system with the results of the functioning of the entire orchestra of mental subsystems, including interpretative ones used for the pragmatics of referring. In the natural sciences, however, one has to follow a different path. The mind in its entirety or the integral person will hardly constitute a unit of analysis that is amenable to a natural science approach. In the natural sciences, we choose as level of analysis those aspects of nature that offer some prospect for constructing explanatory frameworks of sufficient range and depth for some significant range of phenomena. For these kind of abstractions and idealisations a high price has to be paid, namely an increasingly larger distance to our ordinary intuitions about the object of enquiry. Perception theory, which proceeds in line with the methodological principles of the natural sciences, is no exception in this regard. It does not even attempt to save our ordinary intuitions about perception but rather aims, under sharp idealisations, to capture some of the highly abstract principles which are at the core of the operations of our perceptual system. It regards as its unit of analysis a specific subsystem of our mind and attempts to identify the abstract internal principles on which its achievements are based by abstracting away from the contributions of other systems of the mind. This shift of focus, with respect to the unit of analysis, from that of a person to an idealised component of the mind is essential if we are to proceed towards assimilating the study of perception to the natural sciences. Therefore, perception theory cannot proceed without an explicit account of the functional architecture in which the perceptual system is embedded. The perceptual system is only a single specific instrument in an entire orchestra of mental components whose complex interactions bring forth 'perception' in the ordinary sense. What we can consciously experience is only the sound of an orchestra of mental faculties working as a whole, including linguistic and interpretative ones. We have, however, no experiential access to the processes involved that would allow us to identify which instruments make which contributions and the precise way in which they act together. In particular, we have no experiential access to the fundamental principles underlying perception.

Phenomenological observations that appear particularly salient or enigmatic do not necessarily have a particular relevance for perception theory. Although phenomenological observations of various kinds are of prominent heuristic importance for perception theory, they do not possess a kind of 'epistemological superiority'. Thus they are, within a naturalistic inquiry into the principles of perception, on a par with many other sources that provide relevant facts and observations.

While the general idea is unwarranted that fundamental principles of perception can be derived from the structures of experience, arguments can be adduced to support the idea that core aspects of the conceptual structure underlying perception can be explored by and partly revealed by phenomenological observations. Such an idea relies on the assumption that the semantic distinctions and categories of the system of conceptual forms that is at the core of the perceptual system are not critically distorted by idiosyncratic properties of subsequent systems, such as linguistic or interpretative ones, and are appropriately mirrored by the struc- 
ture of phenomenal experience. Although such an assumption appears innocent enough, perhaps even inevitable, it could turn out to be empirically unjustified, either partially or even entirely. However, theoretical considerations can be adduced in favour of the idea that the conceptual structure of subsequent systems, such as imaginative, interpretative or linguistic ones, are based on and have been evolutionary built on the system of conceptual forms that is at the core of the perceptual system. To the extent that such a conjecture is accurate, phenomenal experience - however it is generated by subsequent components - will presumably mirror basic structural properties of the system of conceptual forms, and therefore can be heuristically used for the task of identifying these structural properties. In fact, phenomenological observations are particularly suited for such a task because, as long as they are not contaminated by interpretative activities and common-sense construals, they have the methodological advantage that they exclusively focus on internal structural regularities and bracket the intractable issue of how mental categories map to their alleged 'proper' causal external world antecedent.

\section{Explanatory accounts of perception: Perception as a triggering of conceptual forms}

How can we deal with the attribute of phenomenal realness in explanatory accounts of perception? This question can only be addressed in the context of a general explanatory framework for perception that captures core functional design principles of the perceptual system that are empirically well-supported and conceptually motivated. Any satisfactory theoretical account of perception has to be conceptually capable to appropriately deal with the most fundamental perceptual achievement, namely the activation of meaningful categories by physico-geometric energy patterns. How can a biological system, viz. the perceptual system, deliver, on the basis of physic-geometric energy patterns as inputs, outputs that are organized in terms of meaningful categories? The corresponding theoretical problem can be regarded as the Fundamental Problem of Perception Theory. In traditional approaches, this problem is dodged by describing what is regarded as the mind-independent world in terms of perceptual categories, i.e. by externalising meaning, as it were. In fact, however, the core achievement of our brain to externalise its own semantic categories into what we perceive as the external world is itself in need of explanation by deeper principles. The prevailing penchant of using perceptual categories to describe categories of the external world that allegedly need to be 'recovered' from the sensory input in the process of perception, and hence the tendency to mistake output categories for input categories, trivialises the proper explanatory task of perception theory. This was clearly understood from the seventeenth century (cf. Yolton 1984, 204 ff.) up to the Gestaltists. Also Michotte was keenly aware that the problem of meaning is at the core of any explanatory account of perception and that an appropriate account of the Fundamental Problem of Perception Theory requires a radical re-conceptualisation of traditional modes of thinking about perception. The perceptual entities that make-up our perceived world bear no relation of resemblance to the mind-independent entities by which they are elicited. They are rather, as particularly the Gestaltists have amply demonstrated, mental entities that are occa- 
sioned in the mind by suitable input conditions. In contrast, traditional approaches in perceptual psychology usually conceive of the process of perception as subsequent stages of 'information' processing by which the sensory input is successively transformed, by some associative or inferential machinery, into the percept. As they tend to derive meaning in perception from allegedly external world categories, they see no need for the identification of the internal conceptual structure of perception. Thus, they do not even recognize the Fundamental Problem of Perception Theory as a problem of perceptual psychology, and are conceptually incapable to deal with it.

The inappropriateness of theoretical conceptions that attempt to derive the meaningful categories underlying perception from properties of the sensory input was clearly understood in the seventeenth century and, since then, has been pointed out again and again, notably by the Gestaltists. In corresponding enquiries, it became evident that the problem of perceptual meaning cannot be resolved by deferring the explanatory duty to the sensory information plus some general inferential machinery. Despite these flaws, corresponding frameworks still dominate perceptual psychology. The reasons for this odd situation seem to predominantly lie in the fact that these frameworks are wedded to deeply entrenched common-sense conceptions of perception and explanation, which are illegitimately transferred to scientific enquiry (Mausfeld, 2012).

More recently, in a theoretical convergence of different disciplines a theoretical picture is emerging at the horizon which represents a radical re-conceptualisation of traditional modes of thinking about perception and is conceptually much better suited to deal with the Fundamental Problem of Perception Theory. The emerging theoretical conception binds together some general principles of perception that seem to be conceptually well-motivated and empirically reasonably well-supported. Although it is still very skeletal, its core elements can be clearly discerned. They can be summarized, in a highly abstract and condensed manner, as follows (for a more detail account and some relevant empirical and theoretical evidence see Mausfeld 2010; 2011).

1. The conceptual structure underlying the percept cannot be inferentially attained from the sensory input. The output of the perceptual system, namely meaningful categories, is evidently vastly underdetermined by the sensory input, namely physico-geometric energy patterns. Thus, the core task of perception theory is to understand the internal conceptual structure with which our perceptual system is endowed. The conceptual structure underlying the semantic distinctions that characterise the output of the perceptual system can, by conceptual necessity, only be expressed by a logical language that is strictly more powerful than the logical language by which sensory notions can be expressed. Consequently, the internal structure underlying perceptual meaning - including core notions such as 'Gestalt' or 'perceptual object' cannot be derived, by whatever kind of general inductive machinery, from the sensory input, or, more generally, from experience. 
2. Perceptual meaning is entirely coded within the perceptual system and is part of its biological endowment. As meaningful categories cannot be derived from the input, explanatory needs require us to assume a system of suitable data formats or conceptual forms by which these categories are coded and which mediates between the sensory input and its output. Conceptual forms define the data format of computational processes that generate the output of the perceptual system at its interfaces to subsequent systems. They constitute the minimal meaning-bearing elements of the perceptual system and thus code its 'internal semantics'. In contradistinction to traditional approaches, the 'meaning' of perceptual concepts, such as 'surface', 'illumination', 'actor', or 'event', is defined exclusively in terms of intrinsic features of conceptual forms (subsequent interpretative systems can, of course, extend and refine these meanings). Consequently, there is no explanatory gain to be achieved by introducing a notion of reference to objects in the mind-external world. Corresponding notions of reference, which are at the core of traditional approaches, are notoriously fraught with problems and are, in the context of the natural sciences, of little explanatory avail.

Phenomenological observations as well as experimental findings show that the system of conceptual forms in terms of which we perceive our ambient world is exceedingly rich. Although the structure of conceptual forms is only partly phenomenally expressed, there is a wide range of empirical findings (including experimental findings from ethology) from which relevant insights can be distilled. At its core is the notion of a 'perceptual object'. 'Perceptual objects' differentiate into a structured hierarchy of various types, such as 'physical object', 'biological object', 'other person', 'self', 'tool', 'event', or 'situation', each with its proprietary attributes and relations. Conceptual forms create, as it were, what we perceive as the world out there. They define the way in which we perceptually make sense of the world. Conceptual forms are logically autonomous in the sense that they cannot be decomposed into sensory concepts and cannot be achieved by mathematical transformations of the sensory input. As they cannot be reduced to or inductively derived from the sensory input, they have to be assumed to be part of the biological endowment of the perceptual system. Each type of conceptual forms has its own proprietary kinds of intrinsic attributes. Furthermore, the system of conceptual forms can be assumed to have its own computational principles, which constitute a kind of 'perceptual grammar'. An important class of these principles concerns internal causal analyses. The conceptual forms with which our perceptual system is endowed enable internal causal analyses in terms of 'hidden' dispositional properties of the respective types of perceptual objects, and counterfactual causal analyses (e.g. in amodal completion). These computational principles furthermore include ones that pertain, e.g., to an evaluation metric, to the satisfaction of internal constraints, or to a more global coherence. The perceptual capacity for duplication also seems to have its basis in specific structural and computational properties of the system of conceptual forms (Mausfeld 2011).

3. The input serves as a kind of sign for the activation of biologically given conceptual forms. As the output of the perceptual system cannot be derived from sensory-based computations, the sensory input plays a fundamentally different role from the one alleged in traditional con- 
ceptions (as also Michotte emphasised). The role of the sensory input is to activate appropriate conceptual forms and thus to determine the potential data formats in terms of which input properties are to be exploited by the perceptual system. The relation between the system of sensory codes, i.e. codes yielded by computations on the sensory input, and the system of conceptual forms is a relation between two computational systems that are based on logical languages of different expressive power. The relation between the sensory input and the conceptual forms therefore has to be mediated by some interface or triggering function that takes a sensory input as an argument and calls a set of conceptual forms.

This brief description attempts to abstractly capture the theoretical conception of functional design principles underlying perception that is emerging from various domains of enquiry in the cognitive science, and that was also, albeit in a more implicit and intuitive way, underlying the approaches of Gestalt psychology, and Michotte's experimental phenomenology. An actual theory of perceptual achievements has, of course, to go far beyond such a coarsegrained description of general design principles and deal with issues on a much more finegrained level of explanation. It has, for instance, to identify, for a certain domain of phenomena, the structure and properties of the specific conceptual forms involved, and of the specific computational principles and internal constraints involved in the respective perceptual achievements. An abundance of empirical evidence has been accumulated in the history of perceptual psychology that is of relevance to corresponding issues. However, the available empirical evidence has not yet been fully exploited theoretically, due to the theoretical abstemiousness and a-theoretical orientation that characterise large parts of perceptual psychology.

\section{The attribute 'real' in explanatory accounts of perception}

Our ordinary conception of perception is marked by the conviction that our perceptual categories and attributes are categories and attributes of the external world. In perceptual psychology, this naïve realism seduces us to erroneously employ the categories of output of the perceptual system for a description of the external world and the input. Consequently, traditional approaches see no explanatory need to consider realness as a perceptual attribute. They rather take 'real' to be a kind of identifier for those mind-independent aspects of the ambient world to which perception refers in the external world. This conception finds its expression in the characteristic distinction between 'veridical' and 'illusory' aspects of perception. In the context of a natural science approach to perception, such a distinction is unwarranted and theoretically detrimental (cf. Mausfeld 2002). Yet it underlies almost all traditional accounts. As far as an attribute of phenomenal realness is acknowledged at all in traditional accounts of perception, it is regarded as a kind of derived or subordinate attribute that reflects the degree to which a percept approximates the alleged goal of perception to achieve a more or less veridical seeing of the actual physical situation. The findings of Michotte and many others demonstrate that this idea, and in fact the entire underlying conceptual framework, is utterly inappropriate and flawed, both on empirical and theoretical grounds. 
Our predisposition to take perceptual entities for 'things in the real world' seems to have its roots in functional components that are closely tied to the perceptual system and normally attach to its output a kind of designator that marks it as something pertaining to the mindindependent world. When we see a tree, the corresponding percept automatically and almost irresistibly comes with a marker "my seeing the tree is caused by that there actually is a tree". This built-in 'belief' in the mind-independent existence of the objects of perception has been noted and investigated since the earliest days of perception theory. In Reid's formulation $(1805,471)$ : "When I perceive a tree before me, my faculty of seeing gives me not only a notion or simple apprehension of the tree, but a belief of its existence, and of its figure, distance, and magnitude; and this judgment or belief is not got by comparing ideas, it is included in the very nature of perception." Accordingly, this belief in the mind-independent existence of perceptual objects cannot simply be explained as being the result of our belief-forming capacities, or of reasoning or interpretation. Rather, it seems to be built into the machinery of those components that deal with perception. Therefore, it has to be analysed in terms of intrinsic properties of the functional components involved and must not be confused with the way in which people exploit internal mental structure for acts of referring to things in the world and for distinguishing between appearance and reality. The latter aspects belong the pragmatics of referring and are hence beyond the explanatory scope of perception theory (and, more generally, likely beyond the scope of a natural science approach).

Once we recognise phenomenal realness as a perceptual attribute, we are confronted with a further fundamental problem of perception theory: On the basis of which structural prerequisites and principles can certain activated conceptual forms be 'externalised' and furnished with the attribute of phenomenal realness? We can refer to a corresponding theoretical problem as the Second Fundamental Problem of Perception Theory, in order to distinguish it from the First Fundamental Problem, namely the activation of meaningful categories from physico-geometric energy patterns. The Second Fundamental Problem pertains to the principles underlying and, given specific sensory inputs, regulating our built-in conviction of a mind-independent existence of perceptual objects. It deals with the question: By which kind of internal evaluation functions are activated conceptual forms marked as 'external world' objects?

Although both fundamental problems have been clearly identified in the seventeenth century already, the underlying issues became obfuscated again by the still prevailing empiricist conceptions of perception. The theoretical framework outlined above addresses the First Fundamental Problem, and refers to specific components of the functional architecture, in particular to a system of conceptual forms. In order to address the Second Fundamental Problem, this framework has to be extended appropriately in order to include additional functional components that incorporate evaluation functions with the explanatorily required properties. We therefore have to investigate the kind of functional architecture in which the perceptual system or the system of conceptual forms is embedded, and identify the subsequent functional 
components that deal with the kind of integrative evaluations that underlie the assignment of phenomenal realness. The assignment of degrees of phenomenal realness seems to involve at least two additional functional components beyond the system of conceptual forms, namely (i) a component that expresses activated conceptual forms phenomenally, and (ii) a component that handles the evaluation functions on the basis of which a degree of phenomenal realness can be assigned.

As to the first functional component: The attribute of phenomenal realness can, by definition, only be assigned to perceptual objects that are phenomenally expressed. The relation between the internal conceptual structure underlying perceptual achievements and phenomenal experiences is highly intricate, as for instance indicated by observations on persons who are profoundly deaf and totally blind or suffer from blindsight (e.g. Cowey 2010), and still poorly understood. Fortunately, the specific nature of the relation between conceptual forms and phenomenal experiences is not of crucial importance in the present context, because investigations of phenomenal realness can take this relation for granted, whatever its specific form may turn out to be, and focus exclusively on activated conceptual forms that are expressed phenomenally. It is, however, important, as Michotte already realised, to distinguish the attribute of phenomenal realness of a perceptual object from attributes that pertain to the phenomenal presence or vividness of a perceptual object. Phenomenal presence or vividness is an attribute that is determined by the specific form of the relation between activated conceptual forms and phenomenal experiences. An activated conceptual form that is phenomenally present can become the target of attention (and can be imaginatively retrieved from memory or recreated by a system for imagination). Phenomenal vividness and phenomenal realness are independent attributes and can be entirely dissociated.

As to the second functional component: Phenomenal realness pertains to the impression that a perceptual entity is perceived as having some degree of autonomous existence in our mindindependent ambient world. Phenomenal realness thus can, by its very conception, not simply be an attribute that is intrinsic to phenomenally expressed conceptual forms of the perceptual system, such as 'colour' or 'shape' in the case of 'surfaces', or 'causal' or 'intentional' in the case of 'events'. The assignment of phenomenal realness requires a global assessment of the entire situation in terms of the internal constraints on what is conceived as the 'ambient world' and mind-independent aspects of the percept. Such an assignment must be based on internal causal analyses and integrative evaluations of potential causal sources for the activated and phenomenally expressed conceptual forms.

I will refer to functions that integrate and evaluate different sources of 'knowledge' in order to identify potential causes of the activation of conceptual forms as I-epistemic evaluation functions ('I' standing for 'internal'; cf. Chomsky 2000, 31). Different functional components can provide, in terms of their respective proprietary data format, information that is of relevance for such an identification of potential causes. I-epistemic evaluation functions integrate and evaluate the relevant information from different components according to built-in principles. 
They probably form a computational system of its own, in which other systems, such as the sensory system, the system of conceptual forms, the motorial system, the imaginative system, or higher order interpretative systems provide inputs. Its outputs are used for regulating or controlling computational processes in other systems. The outputs of the system of I-epistemic evaluation functions can, in particular, regulate the 'mental perspectives' by which subsequent interpretative systems can conceive of a given stimulus situation. These 'mental perspectives' can range from mandatory ones (such as the attribute of three-dimensionality in figures 1 and 2, or intentional attributes in the Heider-Simmel demonstration) to ones that can be subjected to attentional or volitional factors (such as the degree of realness of the perceptual objects in figure 2). The human perceptual capacity for duplication, i.e. for employing simultaneous mental perspectives with respect to a given stimulus situation, appears to be based on the availability of I-epistemic evaluation functions that exploit specific structural and computational properties of the system of conceptual forms (Mausfeld 2011).

A central class of these functions deals with the segregation of causes conceived as 'external' from those conceived as 'internal'. They handle the interpretation of activated conceptual forms in terms of 'external world' categories, and thus provide the basis for 'externalising' the outputs of the perceptual system. Such I-epistemic evaluation functions assign activated conceptual forms 'semantic values' by which they are marked as internally or externally caused.

Note that in the context of perception theory, the notion of 'external world' is a purely internal one. As perception theory deals with intrinsic properties of a specific biological system, there is no explanatory gain to be achieved by introducing notions such as 'reference to the external world', 'proper' object of perception, or 'true' causal antecedent of the sensory input. Such notions, which pertain to aspects of pragmatics are, on the contrary, notoriously problematic in the context of the natural sciences (notwithstanding that they constitute indispensable elements in our ordinary or meta-theoretical talk, in which such enquiries are embedded). In the theoretical framework outlined above, I-epistemic evaluation functions replace notions of 'reference to the external world', and perform the tasks that traditional approaches to perception wanted these notions to perform.

The segregation of organism-internal and organism-external causal factors, with respect to various kinds of biological functions, is a most fundamental feature of all living structure, as instructively exemplified by the immune system. In perceptual systems that are based on the integration and evaluations of a rich and highly organised system of codes for internal and external factors that need to be taken into account in order to achieve a biologically appropriate coupling to the environment, the information from different and often conflicting internal and external sources has to be evaluated, with respect to internal requirements and constraints, and integrated.

A simple, yet prototypical example for the segregation of organism-internal and organismexternal pertains to the functional task of disentangling, with respect to the retinal image, 
movements of the eye from the motion of external objects in order to achieve an assessment of the organism-independent motion of the latter. A striking and instructive example pertaining to highly complex perceptual achievements is provided by phenomena related to the socalled rubber hand illusion. If, in an appropriate experimental setting, a rubber hand placed in front of an observer is repeatedly tapped and stroked in precise synchrony with her real hand hidden from view, the touch is actually felt at the spatial location of the dummy hand, and not at the location of the real hand. In such a setting, a dummy hand is instantly assimilated into one's body image, despite the perspicuousness of the situation (e.g. Armel and Ramachandran 2003). The corresponding I-epistemic evaluations are insensitive to the kind of visual inconsistencies involved, and isolated from knowledge and beliefs about the situation.

An influential example that involves achievements of higher-order cognitive capacities and thus falls outside the area of perception theory is the traditional (and epistemologically questionable) distinction between primary and secondary qualities. This distinction has its roots in internal causal analyses that distinguish intrinsic mind-independent real qualities from those that depend on proprietary features of our mental apparatus.

The history of perception theory offers, mostly implicitly or under different headings, a plenitude of instructive enquiries that provide insights into the nature of I-epistemic evaluation functions. However, the prevalence of naïve realistic conceptions about the relation of the conceptual structure underlying perceptual achievements and mind-independent aspects of the world has obfuscated these issues and veiled the problems involved. Consequently, apart from some fairly general ideas, not much is presently known about the specific forms and internal functions of these I-epistemic evaluations. It should be obvious, however, that core perceptual achievements, such as the phenomena of duplication as illustrated by figure 2, cannot simply be explained on the basis of properties of sensory codes, or the system of conceptual forms. Also, the explanatory burden can, for principle reasons and in line with a wealth of corresponding experimental findings, not be deferred to general inferential or interpretative capacities, notwithstanding prevailing empiricist claims to the contrary.

Simple observations on fundamental perceptual achievements suffice to suggest coarse conjectures as to the functions of I-epistemic evaluations. These evaluations are needed, for instance, to resolve violations of internal local and global constraints; define situations of ambiguity or vagueness and provide options for handling them internally; provide various classes of 'internal coherence operators' (e.g. with respect to space); handle identity operators ("looks different but is the same"); provide markers (depending, e.g., on vividness and the potential to interact) for distinguishing between "this is perception" vs. "this is imagination". They furthermore have to integrate perceptual information with internal information about other aspects of the mental status of the perceiver and the context in which the perceiver is situated. I-epistemic evaluation functions are furthermore required to regulate attentional processes in perception. 
In the present context of the attribute of phenomenal realness, corresponding phenomenal observations allow us to tentatively derive some more specific properties of I-epistemic evaluation functions. I will briefly and in an unsystematic way mention a few relevant observations here.

The assignment of a degree of phenomenal realness to a perceptual object can be understood as resulting from a function that evaluates the perceptual object in terms of the potential causal processes that could have given rise to the appearance that is has. Conceptual forms for perceptual entities constitutively comprise dispositional attributes, i.e. attributes that involve projections to other situations and counterfactual conditions. The attribute of phenomenal realness ensures that these hidden attributes are supported by the appearance (rather than being blocked or left undefined). For instance the property of the mirror depicted in figure 2 comprises the dispositional property of being breakable, the beard the dispositional property of being deformable if they are perceived as objects with a high degree of phenomenal realness. If, in contrast, their phenomenal realness is low, these dispositional properties are not supported by their appearance.

Conceptual forms 'expect' that their essential attributes are assigned a value by sensory codes. If values for essential intrinsic attributes are lacking or are in conflict with internal expectations, several options are open. One option could be to fill-in the values in conformity with internal constraints of the system of conceptual forms. A case in point is amodal completion. Although the amodal component of perceptual objects in our ambient world has a certain phenomenal indeterminacy, it nevertheless fulfills a variety of consequences (e.g. pertaining to changes in appearance with viewing perspective) that ensue from the activation of certain conceptual forms. I-epistemic evaluation functions are required to handle the different status of the modal and amodel component. Another option could be to assign to activated but underspecified conceptual forms markers of phenomenal vagueness, or of low phenomenal realness.

A low degree of phenomenal realness of a perceptual object cannot simply be identified with a high degree of 'unrealness'. The attribute 'unreal' broadly pertains to the particular and determinate phenomenal impression that a perceptual object, whether phenomenal real or not, exhibits properties that are perceived as inherently incompatible with properties expected for an 'object in the external world'. Perceptual objects of a low degree of phenomenal realness, such as the head in the drawing in figure 2, do not necessarily go along with a determinate phenomenal impression of unrealness. Also, in the case of four dots arranged in a geometrical way that gives rise to a perceptual object of a square, the perceptual object is phenomenally present, has a low degree of phenomenal realness but still does not give rise to a salient impression of unrealness. In contrast, a scene that is elaborately and lavishly rendered in computer graphics and whose perceptual objects receive a high degree of phenomenal vividness, as well as some degree of phenomenal realness, can still receive a high degree of 'unrealness'. The impression of perceptual objects that are phenomenological vivid but are perceived as 
'unreal' can be accompanied by affective qualities, such as, puzzling, or by esthetic impressions, such as of 'unreal beauty'. An assignment of the attribute 'unreal' to a perceptual object seems to elicit an active search for internal causal analyses by which the impression of 'unrealness' can be defused.
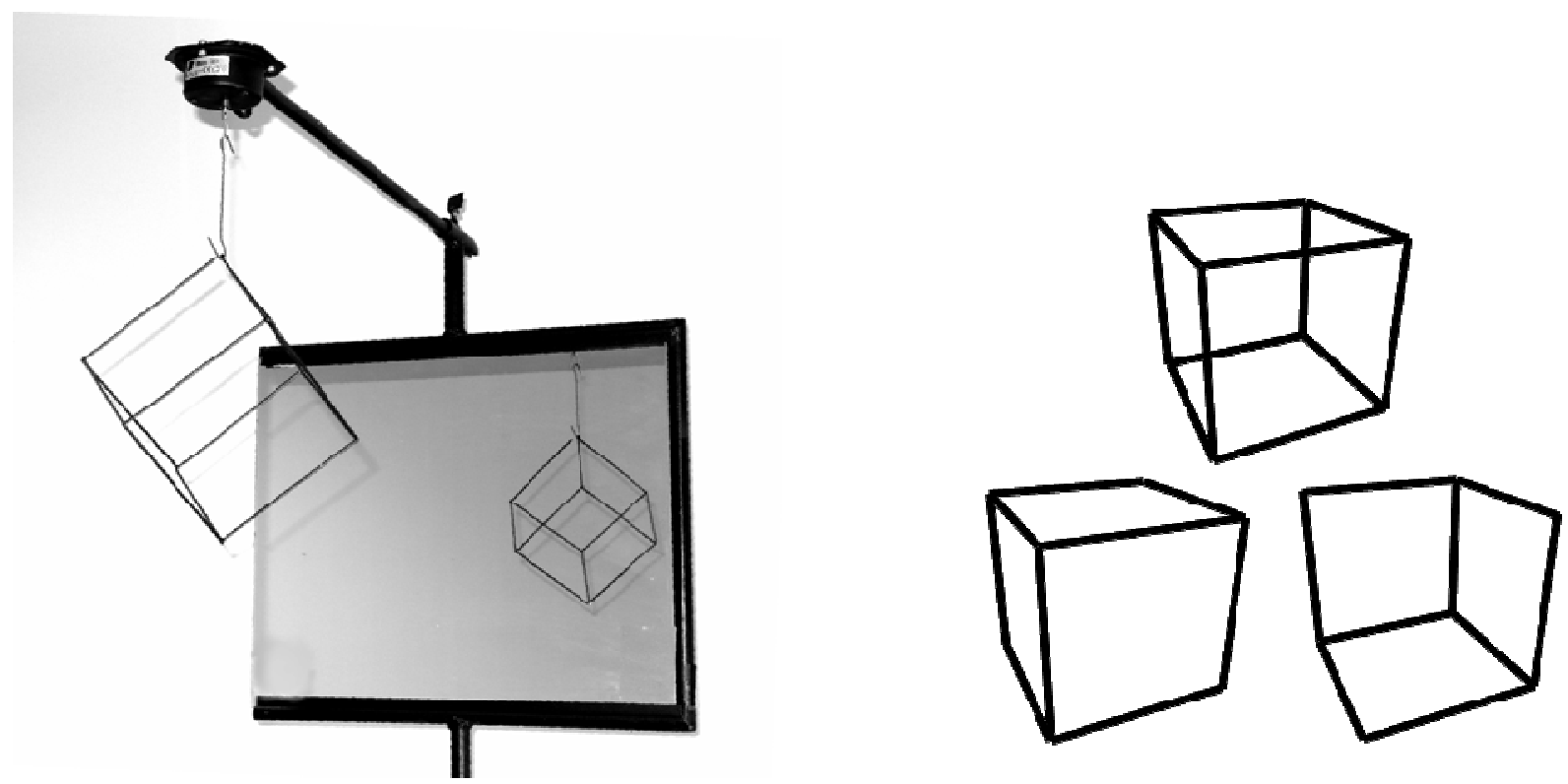

Fig. 3: Left: Apparatus for demonstrating the Hornbostel inversion phenomenon. Right: Perspective view of a wire cube, and its non-inverted and inverted appearances

The Hornbostel inversion phenomenon, illustrated in figure 3, demonstrates that in rare cases a perceptual object can at the same time receive a high degree of phenomenal realness and a high degree of phenomenal unrealness. This means that the perceptual object is associated with the paradoxical experience of encountering a 'real object in the external world' which exhibits properties that are perceived as principally incompatible with properties expected for such objects.

Consider first the simpler situation in which a static wire cube is placed in front of an observer and viewed monocularly. The wire cube obviously receives the maximum degree of phenomenal realness. If the static wire cube is now inverted, some of its intrinsic attributes (i.e. attributes perceived as mind-independent) change. Its shape changes to an irregular hexahedron, which will rotate at its location in various directions depending on head movements of the observer. It thus exhibits properties that violate internal constraints for a mind-independent static wire cube. Accordingly, it receives some degree of phenomenal unrealness, while still having a high degree of phenomenal realness. The simultaneous assignment of both attributes to the same objects generates an I-epistemic tension and elicits I-epistemic attempts to defuse it. This tension can be aggravated by a situation as shown in figure 3 .

In Hornbostel's $(1922,131)$ demonstration, a wire cube slowly rotates in front of a mirror. The cube has to be viewed, preferably monocularly, from a short distance from a position 
frontoparallel to the mirror. If the mirror image of the wire cube is entirely seen inside the wire cube, the cube and its mirror image predominantly appear to turn in the same direction (a corresponding internal constraint of assigning identical motion directions to both cubes would entail that the inner cube is then seen as inverted).

The outer cube, which is physically present in front of the observer, is perceived as a mindindependent element of the ambient world of the observer, and hence is, in the above notation, an element of the overarching system of reference $\Omega$ perceived as 'reality'. As it is perceived as having an autonomous existence in our mind-independent world, it receives a high degree of phenomenal realness. (Of course, the degree of phenomenal realness assigned to the outer cube would be reduced if both cubes were presented on a computer screen.) If the inner cube is perceived as being mediated by a mirror (as is unavoidably the case under binocular viewing), and hence belongs to an autonomous reference frame $\boldsymbol{\omega}$, it receives a lesser degree of realness. Under monocular viewing however, the inner cube tends to detach itself from the mirror and to appear as an autonomous object inside of the outer cube (its perceived distance and size decrease accordingly). In this case, it receives almost the same degree of phenomenal realness as the outer cube.

A depth reversal with respect to a perceived three-dimensional form that appears to rotate usually entails a reversals in the perceived direction of rotation, as already observed by Smith $(1738,61)$. Accordingly, the motion direction of a cube changes when its three-dimensional form is inverted. If the outer cube is seen as non-inverted, the inner cube is (predominantly) perceived as inverted, and both cubes turn in a direction concordant with the physical movement of the wire cube. If the inner cube is seen as non-inverted, the outer cube is (predominantly) perceived as inverted, and both cubes tend to turn in a direction discordant with the physical movement of the wire cube; moreover, the outer cube appears distorted and to also undergo non-rigid transformations during rotation. As the distorted and non-rigid appearance of the outer cube is incompatible with I-epistemological evaluations that the wire object in front of the observer is a rigid cube, the wire object in front of the observer appears somehow 'unreal'.

This impression of 'unrealness' is accentuated if one voluntarily switches the inner mirror cube between its inverted and its non-inverted orientation. By such switches of the inner cube, the outer 'real' wire cube can be made to exhibit properties (rigid cube vs. non-rigid irregular hexahedron) that are mutually incompatible. Accordingly, the outer cube would violate the basic internal constraint that a perceptual object that receives an autonomous existence in the mind-independent world cannot simultaneously, and independently from appropriate changes in external causal factors, exhibit properties that are mutually incompatible. Such switches strongly engender an 'unreal' appearance of the outer cube (which cannot be defused by seeing the object as mediated by its own frame of reference). Corresponding rare cases in which a perceptual object is perceived both as phenomenal real and phenomenal unreal (as they also occur in phenomena of paradox location and ownership experiences of body parts or the en- 
tire body induced by visual-tactile incongruences), are usually associated with particular affective qualities, such as 'weird', 'uncanny', or 'scaring'.

The internal rules for the assignment of the attribute 'unreal' seem to be based on evaluations that go beyond those for the attribute of phenomenal realness. The attribute of phenomenal unrealness appears to be assigned to perceptual objects and scenes in situations in which (i) internal constraints with respect to a perceptual object, or constraints on the relations between conceptual forms are violated, (ii) the violations themselves are phenomenally present, and (iii) the perceptual object would receive a high degree of phenomenal realness if the violation were discarded - as prototypically exemplified by the case of so-called impossible objects.

The maximum value of phenomenal realness is attained for those perceptual objects that perceptually belong to the 'ambient world'. This maximum value can be regarded as a kind of default value for phenomenally expressed conceptual forms. Obviously, the attribute of realness is, in this case, not phenomenally salient. The factors that are eligible as potentially causal relevant and thus enter in corresponding evaluation functions depend on the frame of reference to which a perceptual object belongs. If perceptual objects are (i) perceived as being mediated and thus as being located in an autonomous frame of reference, (ii) essential intrinsic attributes are unspecified or exhibit indefinite relations to other objects (for instance have no definite location in space), or (iii) internal constraints are violated, the degree of realness as determined by appropriate I-epistemic evaluation function will be diminished. For perceptual objects in autonomous reference systems, the deductive consequences and entailment relations of the system of conceptual forms is liberalized, as instructively testified by observations on picture perception.

Evidently, simple observations can already provide a wealth of insights and theoretical reasonable conjectures pertaining to the specific form of the I-epistemic evaluation functions that evaluate and integrate the perceptually relevant information from various kinds of internal and external sources and segregate causes conceived as 'external' from those conceived as 'internal'. However, our current knowledge of the nature of the internal evaluation functions is still most rudimentary, a situation that can only be amended by independent theoretical efforts towards an appropriate theoretical integration of the available empirical evidence. The perceptual phenomena investigated by Michotte provide most relevant whetstones for such an endeavor. 


\section{References}

Albertazzi, Liliana. 2006. Immanent Realism. Introduction to Brentano. Berlin: Springer.

Armel, Kathleen Carrie, and Vilayanur S. Ramachandran. 2003. "Projecting sensations to external objects: evidence from skin conductance response." Proceedings of the Royal Society B: Biological Sciences, 270: 1499-1506.

Benussi, Vittorio. 1911. "Über die Motive der Scheinkörperlichkeit bei umkehrbaren Zeichnungen." Archiv für die gesamte Psychologie, 20: 391-393.

Chomsky, Noam. 2000. New Horizons in the Study of Language and Mind. Cambridge:

Cambridge University Press.

Cowey, Alan. 2010. “The blindsight saga”. Experimental Brain Research, 200: 3-24.

Flavell, John H., Eleanor R. Flavell, and Frances L. Green. 1983. 'Development of the appearance-reality distinction." Cognitive Psychology, 15: 95-120.

Gurwitsch, Aron. 2009. The collected works of Aron Gurwitsch (1901-1973): Volume I: Constitutive phenomenology in historical perspective, edited by Jorge García-Gómez. Heidelberg: Springer.

Heider, Fritz and Marianne Simmel. 1944. "An experimental study of apparent behavior." American Journal of Psychology, 57:243-259.

Hering, Ewald. 1878. Zur Lehre vom Lichtsinne: Sechs Mittheilungen an die Kaiserliche Akademie der Wissenschaften in Wien. Wien: Carl Gerold's Sohn.

Hering, Ewald. 1920. Grundzüge der Lehre vom Lichtsinn. Springer.

Hornbostel, Erich Moritz von. 1922. "Über optische Inversion.“ Psychologische Forschung, 1: $130-156$.

Jaensch, Erich. 1911. "Über die Wahrnehmung des Raumes.“ Zeitschrift für Psychologie und Physiologie der Sinnesorgane. Ergänzungsband: 1-488.

Koffka, Kurt. 1922. "Perception: An introduction to the Gestalt-Theorie." Psychological Bulletin, 19: 531-585.

Koffka, Kurt. 1935. Principles of Gestalt psychology. New York: Harcourt, Brace \& World. 
Kopfermann, Hertha. 1930. "Psychologische Untersuchungen über die Wirkung zweidimensionaler Darstellungen körperlicher Gebilde.“ Psychologische Forschung, 13: 293-364.

Krachun, Carla, Josep Call, and Michael Tomasello. 2009. "Can chimpanzees (Pantroglodytes) discrminate appearance from reality?" Cognition, 112: 435-450.

Lee, Kwan Min. 2004. "Presence, explicated.” Communication Theory, 14: 27-50.

Lenggenhager, Bigna, Michael Mouthon, and Olaf Blanke. 2009. "Spatial aspects of bodily selfconsciousness." Consciousness and Cognition, 18: 110-117.

Marty, Anton. 1879. Die Frage nach der geschichtlichen Entwicklung des Farbensinnes. Wien.

Mausfeld, Rainer. 2002. "The physicalistic trap in perception theory." In Perception and the Physical World, edited by Dieter Heyer and Rainer Mausfeld, 75-112. Chichester: Wiley.

Mausfeld, Rainer. 2003. "Competing representations and the mental capacity for conjoint perspectives." In Inside Pictures: An Interdisciplinary Approach to Picture Perception, edited by Heiko. Hecht, Robert Schwartz, and Margaret Atherton, 17-60. Cambridge, Mass.: MIT Press.

Mausfeld, Rainer. 2010. "The perception of material qualities and the internal semantics of the perceptual system." In Perception beyond Inference. The Information Content of Visual Processes, edited by Liliana Albertazzi, Gert J. van Tonder, and Dhanraj Vishwanath, 159200. Cambridge, Mass: MIT Press.

Mausfeld, Rainer. 2011. "Intrinsic multiperspectivity. Conceptual forms and the functional architecture of the perceptual system. In Interdisciplinary anthropology: Continuing evolution of man, edited by Wolfgang Welsch, Wolf J. Singer, and André. Wunder, 19-54. Berlin: Springer.

Mausfeld, Rainer. 2012. "On some unwarranted tacit assumptions in cognitive neuroscience." Frontiers in Cognition.

Metzger, Wolfgang. 1941. Psychologie. Die Entwicklung ihrer Grundannahmen seit Einführung des Experiments. Darmstadt: Steinkopff.

Michotte, Albert. 1941. "La causalité physique est-elle une donnée phénoménale?" Tijdschrift voor Philosophie, 3: 290-328.

Michotte, Albert. 1946/1963. The perception of causality. New York: Basic Books. 
Michotte, Albert. 1948/1991. "L'énigma psychologique de la perspective dans le dessin linéaire." Bulletin de la Classe des Lettres de l'Académie Royale de Belgique, 34: 268-288. ("The psychological enigma of perspective in outline pictures." In Michotte's Experimental Phenomenology of Perception, 1991, edited by Georges Thinès, Alan Costall, and George Butterworth, Hillsdale, NJ: Erlbaum.)

Michotte, Albert. 1953/1991. "Le participation èmotionelle du spectateur à l'action représentée à l'ècran." Revue Internationale de Filmologie, 4: 87-96. (The emotional involvement of the spectator in the action represented in a film : Toward a theory. In Michotte's Experimental Phenomenology of Perception, 1991, edited by Georges Thinès, Alan Costall, and George Butterworth, Hillsdale, NJ: Erlbaum.)

Michotte, Albert. 1960/1991. "Le réel et l'irréel dans l'image." Bulletin de la Classe des Lettres de l'Académie Royale de Belgique, 46: 330-344. ("The real and the unreal in the image.” In Michotte's Experimental Phenomenology of Perception, 1991, edited by Georges Thinès, Alan Costall, and George Butterworth, Hillsdale, NJ: Erlbaum.)

Musatti, Cesare. 1924. "Sui fenomeni stereocineti." Archivio Italiano di Psicologia, 3, 105120.

Musatti, Cesare. 1926. Analisi del concetto di realtà empirica. Città di Castello, Il Solco.

Musatti, Cesare. 1964. Condizioni dell'esperienza e fondazione della psicologia. Firenze: Editrice universitaria.

Phemister, Margaret R. 1951. "An experimental contribution to the problem of apparent reality." The Quarterly Journal of Experimental Psychology, 3: 1-18.

Pirenne, Maurice H. 1970. Optics, painting \& photography. Cambridge: Cambridge University Press.

Poli, Roberto. 1999. "The concept of empirical reality between logic and psychology: The proposals of the young Musatti." Axiomathes, 10: 127-162.

Reid, Thomas. 1805. An inquiry into the human mind ( $5^{\text {th }}$ ed.). Edinburgh: Bell, Bradfute \& Creech.

Schapp, Wilhelm. 1910. Beiträge zur Phänomenologie der Wahrnehmung. Göttingen: Kaestner.

Smith, Robert. 1738. A Compleat System of Opticks in four books, viz. a popular, a mathematical, a mechanical, and a philosophical treatise. Cambridge: Crownfield. 
Steuer, Jonathan. 1992. "Defining virtual reality: Dimensions determining telepresence." Journal of Communication, 4: 73-93.

Störring, Gustav. 1900. Vorlesungen über Psychopathologie in ihrer Bedeutung für die normale Psychologie. Leipzig: Engelmann.

Stumpf, Carl. 1906a. "Erscheinungen und psychische Funktionen." Abhandlungen der Königlich Preußischen Akademie der Wissenschaften. Philosophisch-historische Classe, 4: 3-40.

Stumpf, Carl. 1906b. "Zur Einteilung der Wissenschaften." Abhandlungen der KöniglichPreußischen Akademie der Wissenschaften, Philosophisch-historische Classe, 4: 1-94.

Stumpf, Carl. 1917. "Die Attribute der Gesichtsempfindungen." Abhandlungen der KöniglichPreußischen Akademie der Wissenschaften. Philosophisch-historische Classe, 8: 1-88.

Wallach, Hans, and D.N. O'Connell. 1953. "The kinetic depth effect.” Journal of Expermental Psychology, 45: 205-217.

Yolton, John W. 1984. Perceptual Acquaintance from Descartes to Reid. University of Minnesota Press. 